\title{
Pequeña teología de la infancia marginada
}

\section{Víctor Codina, Universidad Católica Boliviana, Cochabamba, Bolivia.}

\section{Introducción narrativa}

Era domingo. Al comenzar la celebración eucarística, en una parroquia suburbana del alliplano boliviano, se me acercó una mujer para pedirme que le bendijera una jarra con agua. Le pregunté para qué la queria. Me dijo que acababa de morirsele su hijo de cuatro años. Convenimos en que después de la misa iŕa con ella a su casa. Por el camino me fue contando detalles de la muerte del nifio. Ella era madre soltera, el marido la había abandonado, no tenía más familia que unos primos lejanos con los que vivía. Se ganaba la vida preparando comiditas en el mercado. El niño, hijo único, se había enfermado, fue al médico, le dio remedios, pero aquella noche, repentinamente, había muerto. La mujer no lloraba, no se quejaba, no preguntaba por qué. Atravesamos varias calles embarradas y encharcadas de aguas negras, hasta llegar a su casa

En una habilación grande, habla una mesita con un mantel blanco; y en el centro, entre dos velas encendidas, estaba el niño muento. A un lado, la jarrita de agua bendita. Era un niño hermoso, de rostro moreno. En la habitación habla varias láminas. Una de Jesús, el buen Pastor, con la leyenda del Salmo 23: "El Señor es mi pastor, nada me puede faltar. " En otra lámina, un Niño Jesús sonrosado bendecía con su manita blanca. Llegaron sus primos. Comencé a rezar las oraciones litúrgicas del ritual.

A medida que iba rezando, me inundó una inmensa tristeza, una angustia profunda. Había tanta soledad, tanta pobreza, tanto desamparo, que, poco a poco, la voz se me fue quebrando, se me anudó en la garganta y comencé a llorar, primero pausadamente, luego sollozando, sin casi poder acabar el responso. Abracé a la madre en silencio, y salt llorando de la casa. No sé qué debieron pensar. Pero yo no podía contenerme; y durante un buen rato, de regreso a casa, 
continué derramando lágrimas.

Recordé entonces una escena semejante contada por Mesters en su libro sobre un viaje al Nordeste del Brasil. Había bautizado de urgencia a una nina, y al poco rato murió, rodeada de sus hermanos. Su madre había muerto en el parto, el padre los habia abandonado. La niña se llamaba María Socorro.

Mesters comenta asi el episodio: "María Socorro murió. Vivió 13 dras, nació, vivió, murió. No tuvo registro de nacimiento, ni certificado de defunción. Es como si no hubiera existido. No hablo, apenas lloró. Leve como una pluma, apenas pesaba tres quilos. Pero su muerte pesa, es un peso grande. Ella grita más fuerte que cualquier predicador o político. Ella acusa a la humanidad: '¿Por qué no pude vivir como ustedes? ¿Quién les da el derecho de privarme del derecho de vivir?' Pero estas reflexiones soy yo quien las hago. (...). Sus hermanos, los mismos pobres, solo estaban mirando. No se rebelaron. Lloraron un poco. Encendieron las velas que su hermano Juan habla trafdo. Velaron el cuerpo. Y al anochecer llevaron a su hermanita al cementerio, sin ceremonias, sin certificado de nacimiento ni de defunción, sin padre ni madre. Un "angel" más para engrosar la multitud de ángeles que nos acusan. "Tengan cuidado, dice Jesús, de no despreciar a ningún pequeflo, porque les digo que sus ángeles contemplan continuamente el rostro de mi Padre en el cielo (Mt 18,10)."

Estos no son casos aislados. Los niños en América Latina son las primeras víctimas de la pobreza injusta del continente: nifnos muertos prematuramente, nifios desnutridos, niffos abandonados, niffos sin escolarizar, nifios que trabajan y son explotados, niffos violados, vendidos... Los lustrabotas de La Paz, los gamines de Bogota, las pandillas de menores abandonados de las calles de Sao Paulo, los niffos sin sonrisa de los refugios salvadoreflos, los niffos que se ofrecen a vigilar y lavar los automóviles en los aeropuertos, las niflas que cocinan para sus hermanitos menores y que cargan con ellos todo el dí... Esos nifios muertos violentamente o en masacres represivas, esos nifios que han visto como los soldados mataban a sus padres y violaban a sus hermanas. Esos niffos desparesidos en Argentina, o arrebatados a sus madres violentamente...2

Puebla resume esta grave situación en un breve párrafo: "rostros de niffos, golpeados por la pobreza desde antes de nacer, por obstaculizar sus posibilidades de realizarse a causa de deficiencias mentales y corporales irreparables; los nifios vagos y muchas veces explotados de nuestras ciudades, fruto de la pobreza y desorganización familiar."

Ante esta terrible y provocadora situación ¿tiene la teología alguna palabra que decir?

\section{Una mirada a la tradición teológica}

Los niflos tienen poco lugar en la teología. Diríase que estorban en todas 
partes, tambiên en la teología... Se habla de los nifios en los tratados clásicos del pecado original y del bautismo. La tradición agustiniana ha ligado estrechamente el bautismo de los nifios al pecado original, mientras que la tradición oriental enfoca el baulismo de los niffos en una perspectiva más positiva. Ha habido escribres de la antigiedad, tan rigidos en condenar al infierno a los pobres niños muertos sin baulismo, que fueron llamados "wrturadores de niffos" (tortores infantium). Se comprende que en la edad media, Pedro Lombardo, compadecido de estos nifios muertos sin bautismo, ideara el theologowmenon del limbo, un estado intermedio entre el cielo y el infierno, donde los pobres niños muertos sin bautismo no sufren, aunque tampoco gozan de la visión beatfica de Dios, cuya existencia desconocen. Actualmente esta teoría ha sido abandonada y se confia a la miseriordia de Dios y a su voluntad salvífica universal la suerte de los niffos muertos sin bautismo.

Modemamente la problemática del bautismo de los nifos ha vuelto a actualizarse, sobre todo a partir de las críticas de Karl Barth a esta práctica, considerada por él como una grave herida (grave vulnus) a la Iglesia. De hecho en el primer mundo hay una tendencia a retrasar el bautismo de los nifios, a pesar de las objeciones de Roma a esta praxis." Pero parece que en toda esta problemática la suerte etema de los niffos prevalece sobre la preocupación sobre su vida temporal; o se da obviamente por supuesto que los nifos van a vivir. Pero en el tercer mundo, nacer no significa vivir mucho tiempo, ni menos aún llegar a viejo. En todo caso a los niflos les espera una infancia muy dura y una vida sumamente trabajosa.

También ha sido tratada la problemática de los nif́os desde el ángulo de la teología moral: control de la natalidad, aborto, nuevos problemas de ingenierá genética y de bioética... Pero a todo ello hay que decir que estos problemas tienen un significado muy diferente en el primer mundo y en el tercer mundo. El control de la natalidad libremente escogido por matrimonios del primer mundo, es muchas veces impuesto a las familias del tercer mundo por los países ricos. Por esto la Humanae vitae, tan criticada y contestada en el primer mundo, fue recibida por los cristianos del tercer mundo como un grito profético en defensa de la vida de los pueblos pobres. El aborto, que tal vez en el primer mundo es fruto de una cruel veleidad, en el tercer mundo surge como algo trágico, ante la imposibilidad de mantener en vida a un nuevo hijo. La problemática de los nifios-probeta o de la inseminación artificial y de las "madres prestadas," es inaudita e irreal para los pobres del tercer mundo.

Ciertamente, la historia de la Iglesia testimonia la importancia de la praxis asistencial de las instituciones cristianas para con los nifos. La vida religiosa ha escrito muchas páginas evangélicas admirables en este campo. ${ }^{5} \mathrm{Y}$ el modemo magisterio de la Iglesia tampoco se ha despreocupado de los nifios. En Dives in miseriordia de Juan Pablo II se dice: "no faltan niffos que mueren de hambre a 
la vista de sus madres" (n 11). Y en la reciente exhortación aposiólica Christifideles laice afirma: "la vida de inocencia y de gracia de los niffos, como también los sufrimientos que injustamente les son infligiobs, en virtud de la Cruz de Cristo, obtienen un enriquecimiento espiritual para ellos y para toda la Iglesia Todos debemos tomar de esto una conciencia más viva y agradecida" (n. 47; ver n. 5).

Pero la pregunta subsiste: la teología ¿no tiene nada más que decir sobre la vida marginada de tantos niños del tercer mundo? Los diccionarios bßblicos tratan del niño como símbolo de la imperfección, debilidad, simplicidad, pequeñez y confianza en Dios, pero parecen desconocer el inmenso dolor de tanta infancia marginada. ${ }^{6}$ Aparte de algunas alusiones patristicas de Clemente Alejandrino, León Magno y de autores medievales, como Bemardo, Francisco y Buenaventura, ${ }^{7}$ la tradición no se ocupó mucho de estos problemas, o les dio una orientación exclusivamente espiritual, en la línea del capítulo segundo de la primera carta de Pedro.

Dentro de esta perspectiva espiritual destaca la figura de la carmelita Teresa de Lisieux, quien desarrolla el tema de la infancia espiritual como una espiritualidad de dependencia y confianza filial en el Padre. Siente su pequenez e impotencia, su nada, pero no experimenta propiamente la opresión que sufre la infancia de la mayor parte de la humanidad. Al fin y al cabo, la infancia de Teresa Martín, la futura santa Teresita del Nifio Jesús, esluvo rodeada de carifto, en un ambiente grabificante, privilegiado, mimado, casi pequeño burgués." La misma doctrina de la infancia espiritual, cuando es retomada por algunos teologos de América Latina adquiere un sentido más trágico."

De los teólogos modemos que han reflexionado sobre el terna de la infancia, K. Rahner es quizás el principal. Concibe la infancia no como una etapa superada, sino como una actitud permanente de la vida humana y cristiana, que tiende a que al final lleguemos a ser los ninos que fuimos un día. El ideal es llegar al final de la vida con la frescura, inocencia y confianza filial de la infancia. La infancia es un misterio, cuya plenitud es la filiación divina. La experiencia de sentirse seguro y a salvo, típica de la infancia, es nuclear en la vivencia cristiana de Dios Padre. ${ }^{10}$ Pero lampoco en Rahner aparece la dimensión de la infancia oprimida, propia del tercer mundo, seguramente porque tampoco Rahner vivió de cerca, ni personal ni socialmente, la desgarradora experiencia de una infancia olvidada, oprimida, ultrajada, abandonada.

Más cercano a la experiencia de la infancia del tercer mundo está el escritor judio Elie Wiesel, premio Nobel de literatura, quien narra aquella terrible experiencia vivida en el campo de concentración de Auschwitz, y que ha sido citada por muchos autores. Un dia los prisioneros del campo fueron obligados a asistir a la ejecución de un niffo: un niño judio fue ahorcado en presencia de wodos. En medio de un silencio angustioso, alguien exclam6: "¿Dónde está 
Dios?" Pero en seguida, otro de los judíos presentes respondio: "Aquí, en este niño ahorcado."

\section{Nueva aproximación biblica}

Sin ninguna pretensión de exhaustividad escrituristica ni exegética, destaquemos algunos elementos que parecen importantes en la Biblia sobre este tema, vistos desde América Launa.

Ya en el Génesis nos encontramos con el sacrificio de Isaac (Gn 22, elohista, con elementos yahvistas), que pretende, entre otras intenciones, criticar los sacrificios humanos, concretamente de niños, lípicos de los santuarios cananeos. Los primogénitos, en Israel, como las primicias de la tierra, deben ser ofrecidos a Dios, pero no sacrificados (Ex 13,11). La ley de Israel condena los sacrificios infantiles a Moloch (Lv 18, 21; 20, 2; Dt 12, 31; 18, 10). Sin embargo, en Jerusalén, en el quemadero del Valle de Ben Hinnón (la Gehenna), se había introducido la costumbre de sacrificar, por fuego, a los niños. Los libros de los Reyes aluden a esta terrible práctica: Ajaz mandó pasar por el (uego a su hijo (2Re 16, 3), y lo mismo hizo Manasés (2Re 21, 6). El reformador Josias, en cambio, profanó el valle de Ben Hinnón, para que en el futuro nadie hiciera pasar por el fuego a sus hijos en honor de Moloch ( $2 \operatorname{Re} 23,10)$. Los profetas, por su parte, critican duramente al pueblo por haber introducido esta costumbre pagana en Israel $(J r 7,31 ; 19,5 ; 32,35 ; \mathrm{Ez} 16,21)$.

En el comienzo del Exodo (Ex 1, 15-21) aparece la orden del faraón de matar a lodos los niffos hebreos varones. De esta ley se salva milagrosamente Moisés, "sacado de las aguas" (Ex 2, 5-10). Este texto está en el trasfondo del relato de Mateo sobre la matanza de los inocentes (Mt 2, 13-18), como luego veremos.

El segundo libro de los Macabeos (2Mac 7) nos presenta el episodio del martirio de los siete hermanos junto con su madre. No se trata propiamente de niflos, pero si de jovvenes muchachos, el menor de los cuales es, seguramente, un adolescente $(2 \mathrm{Mac} 7,25)$. Perseguidos en tiempo de Antíoco por su fidelidad a la ley, ofrecen un testimonio claro de la fe en la resurrección a una nueva vida.

Frente a estas situaciones dramáticas de los niños, los profelas anuncian que el nacimiento de un niffo traerá la salvación (ls 9,5-6) y la era mesiánica se describe como reconciliación y convivencia pacífica entre un nif̂o y los animales más salvajes (Is $11,6.8$ ), o como una nueva lierra en la que "no habrá all jamás niffo que viva pocos días (Is 65, 20; $c f$. Is 66, 12-13).

El Nuevo Testamento no nos ofrece una imagen demasiado idilica de los nifnos. El episodio de los inocentes y de la huída a Egipto (Mt 2, 13-18) descrito bajo la inspiración del Exodo, muestra el paralelismo entre Herodes y el faraón y entre Jesús y Moisés: ambos se salvan milagrosamente de una muerte que se abate sobre muchos inocentes. 
Frente a los discípulos que ref̂ian a los nifios que querian acercarse a Jesús, éste los defiende, los bendice y proclama que el reino de los cielos es de los que son como ellos, y que sólo quien reciba el reino como un niño, entrará en él (Mc 10, 13-16 y paralelos Mt 19, 13-15; Lc 18, 15-17).

En otra ocasión, cuando los discípulos disculen sobre quién es el mayor en el reino de los cielos, Jesús llama a un niño, lo coloca en medio de ellos y afirma que hay que hacerse como niffo para entrar en el reino de los cielos, y el que se haga como nir̃o, éste es el mayor en el reino. Luego Jesús se identifica con los nifos: "y el que reciba a un niffo como éste en mi nombre, a mí me recibe" (Mt 18, 5); y amenaza duramente a los que escandalicen a estos pequefios, cuyos ángeles ven continuamente el rostro del Padre (Mt 18, 1-10 y paralelos Mc 9, 33 36; L 2 9, 46-47).

Finalmente en el contexto de la entrada mesiánica de Jesús en Jerusalén, los niflos, en el templo, gritan "¡Hosanna al Hijo de David!" Esio provoca la indignación de los sacerdotes y escribas y la defensa de Jesús con la cita del Salmo 8, 3 (LXX): "de la boca de los niños y de los que aún maman, te preparaste alabanza" (Mt 21, 12-16; los paralelos Mc 11,9-11 y Lc 19, 35-39, no hablan explícitamente de los nifios).

En el Apocalipsis, se establece la pugna entre la Mujer y el Dragón (Apoc 12). La Mujer va a dar a luz a un hijo varón, pero frente a ella está el Dragón dispuesto a devorarlo. La Mujer da a luz, el hijo es arrebatado hasta el cielo y ha Mujer huye al desierto (Apoc 12, 5-6).

Si quisiéramos resumir, recuperarando las líneas de fondo de estos aportes brblicos, deberiamos decir que tanto en el Antiguo como en el Nuevo Testamento la imagen del nino no es nada idflica. Frente al mundo grecorromano que, como el primer mundo modemo, idealiza al niffo, la Biblia en realidad reconoce tanto la inmadurez de la infancia (Le 7,32; 1 Cor 13,11; Gal 4, 1-3; Ef 4, 14; Mt 11, 16), como su debilidad y la confianza en Dios (Mt 7, 9). ${ }^{11}$ Pero en la Biblia, el nino simboliza no sólo la debilidad y la confianza en Dios, sino también la marginación, el peligro de ser sacrificado, eliminado, postergado, perseguido, devorado por los poderosos de este mundo. Frente a esta situación, los profetas asumen la defensa del nino y Jesús llega a colocarlo en el centro del reino, y a identificarse con él. La utopía del reino consiste en un mundo donde el nifo no esté amenazado y pueda vivir en paz.

\section{Reflexión teológica}

Podríamos decir que para la Biblia, los niflos más que personificar la inocencia $y$ la bondad, personifican la vulnerabilidad y la vida amenazada Forman parte de la categoria de los "pequentos" (nepioi), que incluye a los pobres, débiles, enfermos, ignorantes, extranjeros, viudas, ancianos... Los niflos son la expresión más patente de los sin-voz (infantes), de los que sufren 
injustamente la agresión de los fuertes. De ellos es el reino de los cielos.

La identificación de Jesús con los niños (Mc 10, 15; Mt 18, 5; Lc 9, 48), concreta la identificación de Jesús con los pobres (Mt 25,31-45). Y desde esta óptica se puede decir que las afirmaciones biblicas y en especial evangélicas sobre los niños son dialécticas: se afirma su dignidad e importancia, su primacía en el reino, frente a los que ponen como escala de valores la grandeza mundana, el poder, la riqueza, la autosu íciencia, el placer. Esta dialéctica alcanza su punto álgido en la confrontación apocalíptica entre el Dragón y la Mujer que va a dar a luz. En un enfrentamiento entre los poderes de muerte y las fuerzas de vida, entre el homicida desde el comienzo $(J n$ 8, 44) y la nueva Eva, engendradora de vida El niño forma parte de la utopía de la nueva lierra y de los nuevos cielos, mientras que el Dragón es la serpiente antigua En una lectura evangélica y cristiana, la Mujer es María que engendra a Jesús, y Jesús se identifica con el niño - los niffos-, cuya única esperanza es su Madre. En una lectura eclesial, la Iglesia es perseguida en sus hijos pequeños por las fuerzas de la muerte. En una lectura integral la Mujer es la nueva humanidad, el reino de Dios, que engendra vidas frente al anti-reino del mal, del pecado y de la muerte.

Pero estos datos bíblicos deben historizarse. Los conquistadores y primeros evangelizadores de América Latina se escandalizaron de los sacrificios humanos que vieron en diferentes lugares del continente. Pero los conquistadores ofrecieron sacrificios humanos, mucho más numerosos y crueles que los de los indigenas, a su verdadero dios, la codicia de oro y de plata. ${ }^{12}$

Han pasado los siglos, y en América Latina se continúan ofreciendo sacrificios humanos, sacrificios de niflos. De nuevo, como en Caná́n y como en Israel, ninos son pasados a fuego, asesinados, perseguidos, maltratados, lentamente torturados, marginados. Isaac es sacrificado realmente. El faraón continúa asesinando nitos. Herodes sigue matando inocentes. Persiste el escándalo de que los ninos sean marginados de la vida. La Mujer sigue huyendo con sus hijos. El Dragón sigue devorando nifos. Ahora el faraón, Herodes, Antíoco, el Dragón, no tienen rostro. Son siglas, números en bancos, cifras de deuda extema, balanza comercial, fuga de divisas, dinero que se dedica al amamentismo. órdenes secretas de los poderosos, pero el efecto es real: los niffos son sacrificados, rápida o lentamente. Se ha dicho que la tercera guerra mundial ya ha comenzado. Lo que sucede es que en lugar de morir soldados, mueren niños. Desde este continente de muerte y de vida infrahumana, estos datos bíblicos adquieren un especial relieve.

Y en estos niffos Jesús se hace presente. Como en el sacrificio de Isaac, en el sacrificio de estos ninos, hay un misterio pascual de cruz y de resurrección. Los niffos, como corderos mudos llevados al matadero (Is 53, 7), cargan como Jesús, prefigurado por Isaac (Hb 11,19), con el pecado del mundo (Jn 12,9), historizan el Siervo de Jahvé. Es en esta impotencia donde se revela, como en los hermanos 
Macabeos, la esperanza de la resurrección, el poder del Dios de la vida sobre la muerte.

La teología de América Latina, concretamente la teología de la liberación, ha hecho del reino el horizonte de su reflexión. Siguiendo a los evangelios hay que afirmar que en el reino el mayor es el niño, el débil, el pobre, el perseguido, el sin-voz. Esta proclamación profética choca con la cnuel realidad histórica. En la práctica sucede al revés: el niño es el marginado. De ahí la urgencia de una denuncia profética por parte de la Iglesia ante esta situación inhumana. Otros organismos internacionales (UNICEF, Derechos del niño...) han alzado su voz. La voz de la Iglesia no debe enmudecer.

Esta denuncia teológica y eclesial debería mostrar que estas muertes no son casuales, ni sorpresivas. Son fruto de las estructuras de pecado y de injusticia que imperan en el continente. Los niffos son las víclimas inocentes de esta estrategia diabolica de los dioses de la muerte de nuestro tiempo, son las víctimas de los idolos del imperio: el tener, el poder, el saber egoísta, el disfrutar, el abusar de la naturaleza Los mismos que con tanto mimo cuidan a sus hijos, son muchas veces causantes de muertes de otros niflos lejanos, olvidados.

Pero al mismo tiempo es preciso suscitar la esperanza. No se trata de un optimismo fácil, es la certeza de la victoria final, de que la utopía de los profelas será realidad, de que el Caraón, Antíoco, Herodes, ya están vencidos, de que la Mujer ya dio a luz al Hijo, y éste ha de regir las naciones (Apoc 12,5). Los dioses de la muerte, los imperios tienen sus días contados, se dermumbarán, como la estatua de pies de barro (Dan 7). Y por otra parte, los muertos resucitarán, no sólo el último dia, sino también en el pueblo, que recupera la vida y se reanima en la lucha con la sangre de sus mártires, de los inocentes.

En el Antiguo Testamento, frente al dolor injusto de los pobres e inocentes, brota el sentimiento de venganza: "ffeliz quien agarre y estalle contra la roca a tus pequefios!" (Sal 137, 9). En el Nuevo Testamento el misterio pascual ofrece esperanza de victoria, por esto no es necesario recurrir a la venganza, ni a la maldición. Los débiles triunfarán sobre los fuertes, la vida amenazada triunfará sobre los dioses de la muerte, Jesús el Inocente perseguido y asesinado, ha resucitado.

La opción por los pobres comienza por los niffos, los más pequefios entre los pobres: los wawas, los hangos, los tiemos, los pibes, los chavalos, los cabros, los meninos... de América Lalina. Estos niffos de ojos grandes son los que hacen exclamar a C. Mesters:

Siempre cuando veo a los nifios con sus ojos grandes, mirando el mundo, pienso en el capítulo 12 del Apocalipsis, donde habla del Dragón que quiere devorar al niño que va a nacer de la mujer. Una Mujer vestida del sol, con la luna bajo sus pies, grita en dolores de parto, porque llegó la hora de dar a luz. 
Delante de ella un Dragón inmenso, la antigua serpiente está dispuesta a devorar al niño que va a nacer.

Humanamente hablando, quien va a ganar esla lucha es el Dragón. Pero no por ello la Mujer deja de dar a luz. Es dando a luz que ella vence el poder mayor del Dragón. La Mujer, en el momento de engendrar, se encuentra tolalmente indefensa, enteramente entregada a dar vida nueva a otro. ¡El parto es, al mismo tiempo, el momento de su mayor debilidad y de su mayor fuerza! Junமos, ella y el niño, vencen al Dragón. Su debilidad es más fuerte que el poder organizado. Generando hijos, la Mujer mantiene la esperanza de la humanidad contra el poder destructor del Dragón.

Como ya dije, Herodes perdió el nombre, el Dragón se volvió invisible, pero ambos continúan matando a los niños, a la vida nueva que crece en el corazón de tantos. La gente percibe esto aquí, en el campo (...). No sé si todo esto es poesía, pero para mí esto es lo que está aconteciendo en el mundo (...): la lucha entre el Dragón y la Mujer, entre Herodes y los niños indefensos, entre la muerte y la vida, entre la Cruz y la Resurrección, entre el bien y el mal. El mal no va a ganar, porque la resistencia del bien es mayor y más fuerte a largo plazo. Todo esto es para mí una luente de fe, de esperanza, y quiera Dios, sea también una fuente de mayor donación y amor. ${ }^{13}$

Todo ello supone también un cambio en el estatuto epistemológico de la teología latinoamericana. Ya no puede ser solamente una teología fríamente académica. Tampoco es suliciente ya la dimensión orante de la teología, de la que hablaba K. Rahner, una teologia "arrodillada" (kniende Theologie) ante el misterio. Desde América Latina, ante el clamor de la infancia oprimida, surge una teología sollozante, en solidaridad con las madres de todos los inocentes oprimidos. El clamor se vuelve oración; y la oración, llanto. Y la teología se vuelve compasiva, intellesus misericordiae, ante tanto dolor injusto:

Un clamor se ha oído en Ramá, muchos llantos y lamentos:

Es Raquel que llora a sus hijos y no quiere consolarse porque ya no existen (Mi 2, 18, citando a Jr 31, 15).

La teologia de la infancia inocente del primer mundo uno será una coartada para desviar la atención de la trágica realidad del tercer mundo? Seguramente estos gritos molestan. Pero si estos callan, hasta las piedras gritarán (Lc 19, 39; Ha 2, 11). 


\section{Notas}

1. C. Mesters, Seis dias nos poroes da humanidades, Petropolis 1985, p. 41.

2. Vémse los estremecedores relalos recogidos de El Salvador por Marfa Lopez Vigil, en Primero Dios, San Salvador 1988, especialmente, "No se lleven a mi ninol," p. 12; "Mataron a mi papá no solo de bala," p. 14; "Los niños estaban aterrados," p. 31; "Mataron a mi mamá en una barranca", p. 16. Citemos una muestra. "La más pequeña miro todo lo que hicieron a su tata y a sus hermanas. Muda se me ha quedado, sólo llorando pasa, no dice una palabra" (p. 11). También el cine ha recogido esta problemática. Recordemos Los olvidados, Pirote, La historia oficial. entre otros.

3. Puebla 32.

4. V. Codina, D. Irarrázaval, Sacramentos de iniciación cristiana, Madrid 1988, pp. 67-70.

5. M. Mollat Pobres, humildes y miserables en la edad eedia, México, 1988. J. Pixley, C. Boff, Opcion por las pobres, Madrid 1986, pp. 183-213.

6. X. Leon Dufour, Vocabulario de teología biblica, Barcelona 1973, pp. 585-585

7. Clemente Alejandrino, El pedagogo, GCS 12,87-340; San León Magno, Sermo 37 (PL 54, 258s); San Bemerdo, Sermón sobre la conversión de Pablo (PL 183, 365 ab).

8. E. Anilli, "Infancia espiritual" Diccionario de espirirualidad II, Barcelona 1986, pp. 307.

9. G. Gutiérrez, Beber en su propio pozo, Lima 1983, pp. 188-190.

10. K. Rahner, "Ideas para una teología de le niviez," Escritos de Teologla VII, Madrid 1969, pp. 339-356.

11. H. P. Kolvenbach, Der österliche Weg, Freiburg 1988, pp. $154 \mathrm{s.}$

12. G. Gutiérrez, Dios o el oro en las Indias, Lima 1989.

13. C. Mesters, Seis dlas nos poroes da hwmaridades, (Petropolis 1985). pp. 55-57. 